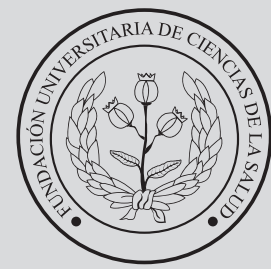

FUCS
Re Ter

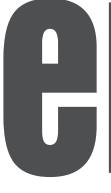

\section{de}

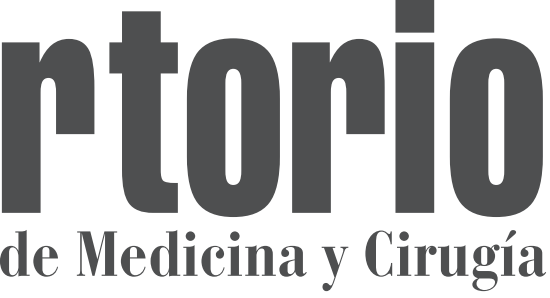

Vol. 280
No1. 2019

ISSN: 0121-7372 • ISSN electrónico: 2462-991X

Artículo de reflexión

\title{
El ser humano visto desde el saber de la medicina familiar
}

Sandra Daniela Rojas ${ }^{a}$

\section{The human being seen from the vantage point of family medicine}

${ }^{a}$ Filósofa, Pontificia Universidad Javeriana, Bogotá DC, Colombia.

${ }^{a}$ Bioética, Pontificia Universidad Javeriana, Bogotá DC, Colombia.

\section{R E S U M EN}

En el campo médico el hombre como objeto que le compete, ha sido analizado en cuanto a sus partes biológicas trayendo consigo una visión incompleta de lo que es el ser humano. En la década de los años 80 se inició en nuestro país la especialidad de medicina familiar, con la cual se buscaba cambiar esta visión, enfocándola hacia la formación integral de los profesionales. El médico familiar trata al ser humano de manera holística, comprendiéndolo más allá de su ser biológico, preocupándose por tratar al hombre y no sólo al paciente.

Palabras clave: holística, medicina, ser humano.

(C) 2018 Fundación Universitaria de Ciencias de la Salud - FUCS. Este es un artículo Open Access bajo la licencia CC BY-NC-ND (http://creativecommons.org/licenses/by-nc-nd/4.0/).

\section{A B S T R A C T}

In the field of medicine, men, who are the object of this discipline, have been simplified to their biological parts, bringing with them an incomplete vision of what the human being is. In the 80s, the specialty of family medicine began in our country, which sought to change this vision based on the comprehensive training of doctors. The family doctor treats the human being from a holistic vision, understanding people beyond their biological being and worrying about treating the human and not just the patient

Keywords: holistic, medicine, human being.

(C) 2018 Fundación Universitaria de Ciencias de la Salud - FUCS. Este es un artículo Open Access bajo la licencia CC BY-NC-ND (http://creativecommons.org/licenses/by-nc-nd/4.0/).

INFORMACIÓN DEL ARTÍCULO

Historia del artículo: Fecha recibido: julio 10 de 2018 Fecha aceptado: julio 30 de 2018
Autor para correspondencia.

Sandra Daniela Rojas

rojas-sandra@javeriana.edu.co
DOI

10.31260/RepertMedCir.v28.n1.2019.882 
INTRODUCCIÓN

El presente escrito es el resultado de la exposición llevada a cabo en la Fundación Universitaria de Ciencias de la Salud, cuyo objetivo propuesto fue que los médicos presentes analizaran no sólo su hacer como médicos sino el objeto de su hacer, como lo es el ser humano, desde una perspectiva diferente para su campo de estudio como lo es la filosofía.

Hipócrates decía que la medicina es "apartar por completo los padecimientos de los que están enfermos y mitigar los rigores de sus enfermedades, y el no tratar a los ya dominados por las enfermedades, conscientes de que en tales casos, no tiene poder la medicina.". ${ }^{1}$ El hacer del médico es curar la enfermedad, pero esta simple respuesta conlleva una visión más profunda, pues el profesional en medicina debe preocuparse por investigar. Curar implica investigar los males que aquejan al ser humano, no sólo los físicos, sino también los emocionales, mentales y aquellos que lo afecten en alguna medida.

Sin embargo, el médico convencional no se preocupa por indagar más allá de lo que sus sentidos le pueden proporcionar, quedándose en la mera biología, ignorando que el ser humano es más que su fisiología. Razón por la cual la visión popular del médico era la de profesionales que han olvidado que tratan a seres humanos iguales a ellos. El médico no se preocupaba por "problematizar el saber y las prácticas médicas. Así como la propia subjetividad médica (lo que los médicos son y cómo se perciben a si mismos)" ${ }^{\prime 2}$, cayendo en la deshumanización de su hacer.

A partir de teorías filosóficas se expuso a los médicos inscritos en la especialidad de medicina familiar lo que es el ser humano y a su vez cómo deben comprenderlo desde su especialidad. El análisis filosófico permitió que los estudiantes se cuestionaran sobre cómo comprendían a los pacientes que trataban y cómo se debían ver a sí mismos dentro de la especialidad. Al finalizar la sesión los estudiantes realizaron la evaluación de la misma, en donde los resultados mostraron satisfacción por la charla y la óptica desde la cual fue dictada, lo cual al ser ajeno a su formación, les permitió analizar su hacer desde otro punto de vista enriqueciendo su saber como médicos.

\section{El método socrático}

La necesidad de problematizar la medicina lleva al autoexamen crítico, en donde deberá indagar si la visión de tratar y conocer al hombre desde su esfera física no alcanza a analizarlo en su totalidad. A través de la mayéutica, método de discusión socrática en la que a partir de las preguntas correctas evidencia aquello que son meras opiniones -doxa- y a su vez nos aproxima a la verdad de aquello que se quiere conocer, sin darnos nunca una respuesta concreta. Así veremos la problemática de que el hacer médico esté enfocado en una sola esfera del hombre.
${ }^{a}$ Sócrates: tú que eres médico, me podrías explicar ¿cuál es el hacer de la medicina?

Médico: la respuesta es simple, tratar y en los casos que es posible, curar la enfermedad.

Sócrates: acabas de decir "en los casos que es posible" ¿por qué es esto?

Médico: porque como bien debes saber, hay enfermedades que no tienen cura.

Sócrates: si entiendo bien, el hacer médico es tratar y curar. $\mathrm{Y}$ hay enfermedades que no se pueden curar, acaso no poder curarlas ¿no es algo que se opone a tu hacer médico?

Médico: no, ya que como sucede con el conocimiento, existen límites que no podemos trasgredir y en nuestro caso, curar todas las enfermedades es nuestro límite.

Sócrates: entonces tu hacer es curar algunas enfermedades.

Médico: sí.

Sócrates: de ser así, me concederías que dijera: el hacer del médico es curar algunas enfermedades y tratar muchas otras.

Médico: sí.

Sócrates: si es así, me podrías decir ¿a quién deben acudir aquellos cuya enfermedad no tiene cura y por lo tanto el médico no puede actuar?

Médico: seguiría acudiendo a los médicos, ya que a pesar de no tener cura la podríamos tratar para mitigar los males que lo aquejan.

Sócrates: así que ¿si mi mal es una enfermedad como el cáncer, debo seguir acudiendo al médico?

Médico: sí, así es, aunque no a cualquier médico, sino al especialista que le compete esa área, en este caso el oncólogo.

Sócrates: dependiendo del mal que me aqueje, tenga cura o no ¿aquel que se llama médico no siempre podrá atenderme?

Médico: será un médico, pero que se especializa en una parte del cuerpo o en una enfermedad.

Sócrates: si el mal que me aqueja está en mi estómago, pero además tengo otro mal en mi espalda, cada médico especialista atenderá esa parte de mi cuerpo por separado.

Médico: si, así sería.

Sócrates: hasta el momento estamos de acuerdo en que el hacer médico es curar algunas enfermedades y tratar muchas otras.

Médico: sí.

Sócrates: y si no estoy mal, cuando hablamos de enfermedades, nos referimos a las del hombre.

Médico: sí, pues las enfermedades de animales ya son asunto del veterinario.

Sócrates: siguiendo esta idea, ¿me concederías que dijera el hacer del médico es el hombre?

Médico: por supuesto, más cierto no podría ser.

Sócrates: y cuando hablamos de hombre, nos referimos a una de sus partes, por ejemplo, su cabeza y no de él como un todo.

${ }^{a}$ El siguiente diálogo es de mi autoría. 
Médico: hablamos de él como un todo, pues la sola cabeza no es el hombre.

Sócrates: si así es ¿por qué la medicina que trata al hombre sólo trata y cura sus partes?

El método socrático en los diálogos de Platón siempre se ha mostrado como una herramienta efectiva al momento de construir conceptos. Para reflexionar acerca de lo planteado en el diálogo recurro a un análisis proposicional de sus partes para evidenciar si aquello que nuestros interlocutores han dialogado no es una opinión que nos aleja de la verdad del hacer médico. Inicialmente partiré de la primera noción del médico establecida en el diálogo.

Premisa 1: como médico trato al hombre.

Premisa 2: la medicina se encarga de la esfera física del hombre.

Conclusión: como médico trato al hombre en lo relacionado con su esfera física.

En este primer esquema no parece haber una contradicción lógica en que el hacer del médico se encuentre limitado a una sola esfera, y que a su vez esta esfera sea segmentada para ser tratada por diferentes especialistas y médicos. Sin embargo, al finalizar el diálogo se ha presentado una problemática ante esta primera afirmación, la cual se evidencia en el siguiente análisis proposicional.

Premisa 1: como médico trato al hombre.

Premisa 2: el hombre no se comprende desde el examen de sus partes.

Conclusión: como médico comprendo al hombre desde el examen de sus partes.

En el segundo esquema se visualiza el error lógico en el ámbito médico de conocer al hombre en relación con sus partes. La medicina convencional ha tratado al hombre desde esta limitada visión, razón por la cual estableció una rama que trate al hombre como un todo, la medicina familiar. Esta área no se limita a una sola esfera sino que se encarga de tratar al ser humano considerando cada ámbito que lo determina, preocupándose por comprender qué es el hombre. Inquietud que desde la antigüedad ha sido una necesidad en la ejecución del hacer médico: "Dicen algunos médicos y sabios que no sería posible saber medicina sin saber qué es el hombre; que, por el contrario, eso es algo que debe aprender el que quiera curarlo correctamente"1

\section{¿Qué es el hombre?}

Para responder a esta pregunta es necesario recurrir a algunas posturas filosóficas que se aproximen a aquello que define al hombre. Para Descartes, el ser humano no se determinaba a partir de su esfera fisiológica, sino que aquello que lo hace ser se encontraba más allá de la experiencia sensible.

No soy esta reunión de miembros llamada cuerpo humano; no soy un aire sutil y penetrante difundido por todos esos miembros; no soy un viento, un soplo, un vapor, ni nada de cuanto pueda fingir e imaginar, puesto que ya he dicho que todo eso no era nada, y sin modificar ese supuesto, hallo que no dejo de estar cierto de que soy algo. ${ }^{3}$

El hombre se definía desde su capacidad de pensar, cogito ergo sum. ${ }^{b}$

¿Qué soy, entonces? Una cosa que piensa. Y ¿qué es una cosa que piensa? Es una cosa que duda, que entiende, que afirma, que niega, que quiere, que no quiere, que imagina también, y que siente. Sin duda no es poco, si todo eso pertenece a mi naturaleza. ¿Y por qué no habría de pertenecerle? ¿Acaso no soy yo el mismo que duda casi de todo, que entiende, sin embargo, ciertas cosas, que afirma ser ésas solas las verdaderas, que niega todas las demás, que quiere conocer otras, que no quiere ser engañado, que imagina muchas cosas - aun contra su voluntad - y que siente también otras muchas, por mediación de los órganos de su cuerpo?³.

Descartes afirmaba que el hombre era una res cogita, una cosa que piensa, determinada por todas las facultades de la mente como la imaginación. Sin embargo, la parte fisiológica no era algo relevante para su definición. Para él, el hombre es más que las partes físicas con las que experimenta el mundo.

Dos siglos después Kant estableció aquello que definiría al hombre a partir de la formulación de su imperativo categórico ${ }^{c}$, el cual versa así: "obra de tal modo que uses la humanidad, tanto en tu persona como en la persona de cualquier otro, siempre como un fin al mismo tiempo y nunca simplemente como un medio". ${ }^{4}$ El ser humano es un fin en sí mismo, esto quiere decir que es capaz de proponerse fines -metas- y que puede hacer suyos los fines de los demás -sólo aquellos que no atenten contra su integridad moral-. Desde esta perspectiva, el ser humano es un fin y un medio para el cumplimiento de los fines de los otros. Pero no se debe comprender al hombre desde una sola perspectiva, es decir como un mero medio, sino que debe ser visto como este alguien que hace suyo los fines de otros; es un medio para lograr las metas de otros y al mismo tiempo es un ser con fines propios que otros deben ayudarle a conseguir.

Desde la perspectiva de Kant, al igual que Descartes, aquello que da razón de qué es un ser humano no está relacionado con la fisiología, sino con una capacidad a priori -anterior a la experiencia sensible-. El hombre no es solo lo físico, hay una esfera inteligible, subjetiva, emocional, que conforma lo que denominamos ser humano. No se trata de una dualidad

${ }^{b}$ Pienso luego existo,

'Imperativo categórico "obra como si la máxima de tu acción debiera tomarse por tu voluntad, ley universal de la naturaleza" (Kant, 2009, p.107) A partir de esta formulación, se da una segunda formulación en relación con el hombre. 
cuerpo-alma, sino en un sentido más aristotélico ${ }^{\mathrm{d}}$ en donde el ser humano es una sola realidad compuesta por diferentes elementos.

\section{El hombre como totalidad}

Ahora bien, ya habiendo determinado que el ser humano no sólo tiene una dimensión material, se evidencia la necesidad de un área médica no limitada a un solo enfoque para tratarlo, esa es la medicina familiar. Para mostrar este punto, retomaré el análisis proposicional realizado antes, con algunos cambios enfocados para dilucidar el hacer del médico familiar.

Premisa 1: como médico familiar trato al hombre.

Premisa 2: el hombre se comprende como la totalidad de sus partes.

Conclusión: como médico familiar trato al hombre como la totalidad de sus partes.

En el trabajo de la medicina familiar el hombre se comprende desde la esfera social, psicológica y biológica, teniendo en cuenta al individuo, la familia y la comunidad; el hacer del médico familiar se realiza desde la relación de las partes con un todo y viceversa, un todo determinado por sus partes. Visión similar a la obra de las manos de Escher que se dibujan mutuamente.

"En el dibujo de Escher observamos que ambas manos se dibujan mutuamente. Esto implica que establecen recíprocamente sus condiciones de creación. Más precisamente, su determinación recíproca los extrae del resto del dibujo, permitiéndoles conformar una unidad". 5

El hacer médico convencional no trata la unidad del ser humano, sino que la segmenta, rompiendo esta integridad natural. Desde el hacer del médico familiar, esta perspectiva del ser humano segmentado ha sido cambiada por el ser humano que se autodetermina como un todo en relación con sus partes.

\section{El médico familiar, aquel que salió de la caverna ${ }^{\mathrm{e}}$}

La unidad natural del hombre es el fenómeno del cuál se encarga el médico familiar. Este médico es el hombre que se ha liberado de las cadenas dentro de la caverna y ha visto la luz fuera de esta. En la caverna se han quedado los médicos convencionales, quienes consideran que la verdad de su hacer es tratar al hombre desde las partes sin dirigirse al todo. El médico familiar ha salido a la luz y ha visto que lo que conoció como médico eran sólo las sombras de los objetos reales que se encontraban fuera de la caverna.

Ya fuera de la caverna, el médico familiar ha descubierto cuál es el verdadero fenómeno del que se encarga su saber, el hombre. Pero no es un hombre que se refleja en las sombras, como se le hacía pensar dentro de la caverna de la medicina convencional, sino que es un hombre más allá de lo que sus sentidos podían percibir en la oscuridad. El hombre que es el hacer de la medicina familiar es un microcosmos, "un todo inescindible en partes que posee en sí mismo la capacidad de autorregularse".6. Ahora ya fuera de la caverna el médico familiar que conoce la verdad de su hacer, debe seguir indagando para conocer más acerca del hombre y en un futuro volver a la caverna y mostrar la verdad de la que ha sido beneficiario.

\section{CONCLUSIONES}

Comprender al ser humano es una necesidad del saber médico que la medicina familiar se ha encargado de realizar desde la totalidad del ser. Esta visión del ser humano en la que la medicina familiar se especializa, debe ser el canon en las diferentes ciencias de la salud, pues el hombre es un fin en sí mismo, que no puede ser tomado solo como un medio para el cumplimento de la labor profesional.

Dilucidar al hombre como microcosmos conlleva que tratar al paciente se transforme en tratar a la persona, alguien que piensa, siente, imagina, quiere y que por ende necesita ser comprendido más allá de su esfera física. De esta forma se espera que el médico familiar trate a las personas en la ejecución de su profesión, pues en el centro del área de la medicina familiar se encuentra comprender al ser humano como este todo inescindible.

\section{AGRADECIMIENTOS}

Agradecimientos a la doctora Karen Chamorro de la Fundación Universitaria de Ciencias de la Salud, quien me brindó el espacio para dictar esta charla y me ha apoyado en la realización de mi trabajo.

\section{REFERENCIAS}

1. Kant, I. Fundamentación Metafísica de las Costumbres. M. G, Morente (trad). Madrid: Tecnos; 2009.

2. Hipócrates. Tratados. C. García (trad). Madrid: Gredos; 2007.

3. Díaz Amado, E. Filosofía de la medicina: la necesidad de una perspectiva crítica en Colombia. Revista Latinoamericana de Bioética. 2016:17(1):102-123

4. Varela, F. El fenómeno de la vida. Santiago de Chile: Dolmen Ediciones; 2002.

5. Alby, JC. (2004). La concepción antropológica de la medicina hipocrática. Enfoques. 2004:16(1):5-29.

6. Descartes,R. Meditaciones Metafísicas. V. Peña (trad). Madrid: Alfaguara; 1977.

\footnotetext{
${ }^{d}$ Para Aristóteles todo cuerpo está constituido de materia y forma, en el ser humano la materia se relaciona con el cuerpo y la forma con el alma. Dos dimensiones que hacen parte de una misma realidad.

${ }^{e}$ Me refiero a la alegoría de la caverna de Platón. En esta, dentro de una caverna hay unos hombres atados, mirando siempre hacia la misma dirección, aquello que pueden ver son las sombras que se producen de la poca luz que entra a la caverna. Un dia, uno de estos hombres se libera y sale de la caverna, percatándose que aquella realidad que habia creido verdad en las sombras de la caverna eran solo los vestigios de la realidad que se encontraba afuera en la luz.
} 